\title{
Qualitative and quantitative analysis of pawpaw (Carica papaya) leaf extract and its antimicrobial effect in animal production
}

Omidiwura, B. R. O.

Department of Animal Science, University of Ibadan, Ibadan, Nigeria

Abstract Corresponding author: richardwura@gmail.com; +2347082077886

In order to improve livestock production and curb the losses from diseases occurrence in livestock, producers resort to the use of antimicrobials as growth promoters to inhibit the growth of disease-causing organisms. Freshly harvested pawpaw leaves were extracted using three solvents: ethanol, methanol and n-hexane and their phytochemicals determined using standard procedure. The inhibitory activities of the extracts at low (200ppm) and high (1000ppm) concentrations against Aspergillus niger and Escherichia coli were also determined. Results obtained showed that alkaloid, flavonoid, saponin, tannin and cardiac glycosides were present while anthraquinone was absent. The percentage yield of phenols using methanol $(0.115 \%)$ and ethanol $(0.214 \%)$ solvents were similar but lower than $n$ hexane yield $(0.450 \%)$. Also the yield of flavonoid using methanol $(0.700 \%)$ is significantly $(p<0.05)$ higher than the yield using other solvents. The yield of phenols using methanol $(0.480 \%)$ and ethanol $(0.470 \%)$ solvents were identical but higher than $n$-hexane yield $(0.400 \%)$. At low concentration, it was observed that the inhibitory concentrations of pawpaw leaf extract against bacteria by control, streptomycin $(1.2 \mathrm{~cm})$ was significantly $(p<0.05)$ higher but similar to the extract from methanol solvent $(1.1 \mathrm{~cm})$. Methanol extract inhibition was also similar to ethanol $(1.0 \mathrm{~cm})$ but higher than $n$-hexane $(0.0 \mathrm{~cm})$. At high concentration, the inhibitory activity of the ethanol extract $(1.2 \mathrm{~cm})$ was significantly $(p<0.05)$ higher than the control $(0.7 \mathrm{~cm})$ and the least observed in $n$-hexane $(0.0 \mathrm{~cm})$ extract. The inhibitory concentrations of pawpaw leaf extract against fungi Aspergillus niger at low $(2.2 \mathrm{~cm})$ and high $(2.2 \mathrm{~cm})$ concentrations, the methanol extract was observed to be significantly $(p<0.05)$ higher than other extracts including control.

The results suggest that using methanol-extracted pawpaw leaf as alternatives to synthetic antibiotic in animal production is effective against microbial organisms. Thus the occurrence of resistance to antibiotic or its residues on animal products will be reduced.

Keywords: Pawpaw; microbes; extraction solvents; phytochemicals; phytobiotics

\section{Introduction}

In order to improve livestock production and curb the losses from diseases occurrence in livestock animals, livestock producers resort to the use of antimicrobials to inhibit the growth of diseases causing organisms as well as growth promoters. It is acknowledged that the antimicrobial use is one of the most successful chemotherapies against diseases causing organisms (Guyue et al., 2014). Various antimicrobials have made significant contributions for the prevention, control and treatment of infectious diseases in animals since 1940's
(Forman and Burch, 1947). The presence of antimicrobial-resistant non-pathogenic commensal bacteria on farms is considered a problem, as it provides a pool of transferable resistance genes (Defrancesco et al., 2004). Also there is the problem of residual effects of drugs on animal products as well as high cost of the drugs and coverage area. However, available evidence indicates that indigenous health practices including medicinal plants are still being used to handle animal health problems in all livestock production systems (Maeda- 


\section{Antimicrobial effect of Pawpaw leaf extract in Animal Production}

Machang'u et al., 1997; Minja, 1999). Since drugs and antibiotics are used in poultry feeds to maximize the efficiency of production, product quality and in the of control diseases, therefore, plants and plants extracts from herbs and spices which are known to have medicinal properties can be used as alternatives to control diseases and improve efficiency because they are known to contain bioactive compounds like tannins, saponins, alkaloids etc. that have inhibitory activities against diseases causing organism. Plant derived natural products represent an attractive source of antimicrobial agents since they are natural, have manageable side effects and available at affordable prices and readily available. Many of these plants extract have also been used as feed additives and have been proven to improve gut integrity of monogastric animals. Many of the medicinal plants are available but the interest of this study is on Carica papaya.

Several chemicals are found in different parts of pawpaw (Carica papaya) the leaves, the stems and fruits. Large amounts of latex are found in the leaves, stem and fruits (Adam et al., 2014). The latex known as vegetable pepsin is rich in papain and chymopapain. It also has proteins like linamarase, protease inhibitors, and chinitasis. The leaves contain glycoside carposide, cardiac glycosides, tannins, flavonoids, saponins, alkaloids, anthraquinones, steroids, reducing sugars, cardenolides and phenolics compounds while the seeds contain myrosinase, caricin and sinigrin glycosides (Adam et al., 2014). The fresh green extract act as antiseptic and dried leaves are best as a tonic and blood purifier (Nwofia et al., 2012). There is, therefore, the need to determine the phytochemical composition and investigate the antimicrobial properties of Carica papaya leaves against pathogenic fungus (Aspergillus niger) and bacterium (Escherichia coli) using different solvents.

\section{Materials and methods Plant collection and identification}

Fresh samples of pawpaw leaves were collected in the Department of Animal science, Faculty of Agriculture and Forestry, University of Ibadan.

\section{Experimental area}

The extractions, phytochemicals analysis and antimicrobial activities were carried out in laboratories of the Department of Animal Science, University of Ibadan. Nigeria

\section{The extraction process}

The leaves were cleaned with tap water and later with distilled water, then chopped on a cutting board before loading into the soxhlet apparatus. Three solvent (methanol, ethanol and n-hexane) were used for the extractions. The temperature of the heating mantle was set at the boiling point temperature of each of the solvents during extraction. The extracts were then poured into beaker and placed in a water bath and the temperature set to boiling point of each solvent to evaporate the solvent and obtain the pawpaw juice.

\section{Phytochemical screening methods}

A portion of the concentrated extract was used for the screening tests, both qualitative and quantitative analyses, using standard procedure as described by Edeoga et al. (2005).

Preparation of bacterium and fungus seeded plates

The culture media (nutrient agar and potato dextrose agar) were prepared according to manufacturer's design. $7 \mathrm{~g}$ of the nutrient agar powder and potato dextrose agar were weighed into separate $250 \mathrm{~mL}$ conical flask, dissolved in distilled water and thoroughly mixed using stirrer and then made up to 


\section{Omidiwura}

$250 \mathrm{~mL}(7 \mathrm{~g} / 0.4 \mathrm{~L})$. They were well corked using foil paper, placed in a pressure cooker and heated for 30 minutes for sterilisation. The media were then allowed to cool to about $45^{\circ} \mathrm{C}$ before pouring it into sterile petri dishes and allowed to solidify. A $5 \mathrm{~mm}$ cork borer was then used to create wells ( 8 wells). $5 \mathrm{~mL}$ of the extracts were then introduced into the wells using a syringe and allowed to be absorbed by the media for about 10 minutes. The bacterium, (Escherichia coli) and fungus, (Aspergillus niger) were then placed at the centre of their respective petri dishes and incubated at $31^{\circ} \mathrm{C}$ for 24 hours.

200ppm (low) and 1000ppm (high) of extracts concentrations were used in the puncture holes for inhibitions.

\section{Measurement of zone of inhibition}

The diameter of the zone of inhibition or clear zone surrounding the well was measured using a ruler. The readings were taken in triplicate as suggested by Zaria et al. (1995). The average was taken to represent the zone of inhibition.

\section{Statistical analysis}

Data obtained were subjected to analysis of variance using SAS (2008). Means were separated using Duncan's Multiple Range Test (DMRT) of the above software package

\section{Results and discussion}

The result of qualitative analysis of phytochemical constituents of pawpaw leaf extract is shown in Table 1. The pawpaw leaves extracts using methanol, ethanol and n-hexane solvents have tannin, saponin, phenol, cardiac glycoside, flavonoids and alkaloids. The methanol extract has shown to contain more saponin $(++)$ than the ethanol and n-hexane extract. Meanwhile none of the solvent extracts has anthraquinone. The presence of tannin, saponin, flavonoids, alkaloids, phenols in the ethanol, methanol and n-hexane extract of pawpaw leaves is in agreement with research work by Doughari (2006) while the absence of anthraquinone in the present study contradicts the findings of Doughari (2006) but in accordance with the research work carried out by Ajani et al. (2013). Isela et al. (2014) reported that the presence or absence of metabolites may be due to differences in polarity of the solvents used for the extraction.

Table 1: The results of qualitative analysis of phytochemical constituents of pawpaw leaf extract

\begin{tabular}{llll}
\hline Phytochemical & Methanol extract & Ethanol extract & n-Hexane extract \\
\hline Tannin & + & + & + \\
Saponin & ++ & + & + \\
Phenols & + & + & + \\
Anthraquinones & - & - & - \\
Cardiac glycosides & + & + & + \\
Flavonoids & + & + & + \\
Alkaloids & + & + & + \\
\hline+ means the presence of the phytochemicals; - means the phytochemical is absent
\end{tabular}

The quantitative analysis of phytochemicals constituents of pawpaw leaves is reported on Table 2. The percentage yield of phenols using methanol $(0.115 \%)$ and ethanol $(0.214 \%)$ solvents were similar $(\mathrm{p}>0.05)$ but lower than $n$ hexane yield $(0.450 \%)$. Also the yield of flavonoid using ethanol $(0.500 \%)$ is similar to n-hexane $(0.480 \%)$ but significantly $(p<0.05)$ lower than the yield using methanol $(0.700 \%)$. The percentage yield of phenols using methanol $(0.480 \%)$ and ethanol $(0.470 \%)$ solvents were similar $(\mathrm{p}>0.05)$ but higher than $n$-hexane yield 


\section{Antimicrobial effect of Pawpaw leaf extract in Animal Production}

$(0.400 \%)$. Brun et al. (1993) concluded that the quantity of chemical substances varies in the fruit, latex, leaves, and roots and varies with the extraction method, age of the plant part, and the cultivar and sex of the tree.

Table 2: Results showing quantitative analysis of pawpaw leaves of pawpaw leaf extract

\begin{tabular}{llll}
\hline & \multicolumn{3}{c}{ Percentage yield (\%) } \\
Phytochemicals & Methanol extract & Ethanol extract & n-Hexane extract \\
\hline Phenols & $0.115 \pm 0^{\mathrm{b}}$ & $0.214 \pm 0.001^{\mathrm{b}}$ & $0.450 \pm 0.01^{\mathrm{a}}$ \\
Flavonoids & $0.700 \pm 0.05^{\mathrm{a}}$ & $0.500 \pm 0.005^{\mathrm{b}}$ & $0.480 \pm 0.005^{\mathrm{b}}$ \\
Alkaloids & $0.480 \pm 0.01^{\mathrm{a}}$ & $0.470 \pm 0.01^{\mathrm{a}}$ & $0.400 \pm 0^{\mathrm{b}}$ \\
\hline${ }_{\text {abc }}$ means with different superscript are significantly different $(\boldsymbol{P}<0.05)$ &
\end{tabular}

The inhibitory concentrations of pawpaw leaf extracts against bacteria are shown on Table 3. At low concentration, the zone inhibited by control, streptomycin $(1.2 \mathrm{~cm})$ is significantly $(\mathrm{p}>0.05)$ higher but similar to the extract using methanol solvent $(1.1 \mathrm{~cm})$. Methanol extract inhibition is also similar to Ethanol $(1.0 \mathrm{~cm})$ but higher than n-hexane $(0.0 \mathrm{~cm})$.

At high concentration, the inhibitory activity of the Ethanol extract $(1.2 \mathrm{~cm})$ was significantly $(p<0.05)$ higher than the control $(0.7 \mathrm{~cm})$ and the least observed in nhexane $(0.0 \mathrm{~cm})$ extract. The Methanol extracted pawpaw leaf was highly comparable to the control at low concentration in the inhibition against bacteria. This may probably be due to the quantity and quality of the phytochemicals it extracted. These phytochemicals are known to confer resistance of plants to bacteria, fungi and pest (Srinivasan et al., 2001).

Table 3: Inhibitory concentrations of pawpaw leaf extract against bacteria

\begin{tabular}{lll}
\hline & \multicolumn{2}{c}{ Zone of inhibition $(\mathrm{cm})$} \\
Extract & Low concentration & High concentration \\
\hline Methanol & $1.1 \pm 0.01^{\mathrm{ab}}$ & $0.4 \pm 0^{\mathrm{c}}$ \\
Ethanol & $1 \pm 0.1^{\mathrm{b}}$ & $1.2 \pm 0^{\mathrm{a}}$ \\
n-Hexane & $0 \pm 0^{\mathrm{c}}$ & $0 \pm 0^{\mathrm{d}}$ \\
Control $^{*}$ & $1.2 \pm 0.1^{\mathrm{a}}$ & $0.7 \pm 0.1^{\mathrm{b}}$ \\
\hline${ }^{*}$ Control is streptomysin & &
\end{tabular}

The results from Table 4 showed the inhibitory concentrations of pawpaw leaf extract against fungi Aspergillus niger. At low $(2.2 \mathrm{~cm})$ and high $(2.2 \mathrm{~cm})$ concentrations, the methanol extract was observed to be significantly $(\mathrm{p}<0.05)$ higher than other extracts including control. Thus, the methanol extract has the highest inhibitory activity against Aspergillus niger.

Table 4: Inhibitory concentrations of pawpaw leaf extract against fungi

\begin{tabular}{lll}
\hline Extract & Low $(\mathbf{c m})$ & High $(\mathbf{c m})$ \\
\hline Ethanol & $1.6 \pm 0.05^{\mathrm{c}}$ & $1.8 \pm 0.2^{\mathrm{c}}$ \\
Methanol & $2.2 \pm 0^{\mathrm{a}}$ & $2.2 \pm 0^{\mathrm{a}}$ \\
n-Hexane & $0 \pm 0^{\mathrm{d}}$ & $0 \pm 0^{\mathrm{d}}$ \\
Control* & $1.6 \pm 0^{\mathrm{b}}$ & $1.8 \pm 0^{\mathrm{b}}$ \\
\hline${ }^{*}$ Control is Copper sulphate & &
\end{tabular}

From these results, the methanol extracted pawpaw leaf, at a low concentration was observed to have better inhibitory activity against the test bacteria and fungus. At a high concentration, the inhibitory activity of methanol extracted pawpaw leaf is 


\section{Omidiwura}

reduced. Meanwhile the inhibitory activity of the methanol extract against the test fungus was the same at high and low concentrations and the methanol extract has the best inhibitory activity compared to ethanol and n-hexane. This means methanol extract has the same efficacy at different concentrations against the test fungus. The result of the methanolic extract is in compliance with the findings of Anibijuwon and Udeze (2009) that the methanolic extract of pawpaw leaf has a high antimicrobial property at low concentration.

Ethanol has the best inhibitory activity against the test bacteria at high concentration. The inhibitory activities of ethanol extract against the test bacteria at high concentration is in compliance with the works of Chandra et al. (2011), Mangalanayaki and Nirosha (2013) and Sumathi and Gowthami (2014). At low concentration however, the inhibitory activity of ethanol is lower than that of the antibiotic used. Meanwhile its inhibitory activity against the test fungus is lower than that of methanol and control at low and high concentration. The lower efficacy of pawpaw leaf extract at low concentration is in agreement with the work of Satyapal et al. (2013). This indicates that the efficacy of ethanol extract as antibacterial was low and therefore, the possibility of the test bacteria developing resistance to the leaf extract. It can be deduced that the efficacy of ethanol as antifungal was low compared to the control and methanol extract and it cannot be solely depended on as antifungal against the test fungi.

The n-hexane extract did not inhibit any antibacterial activity at low and high concentration which means that n-hexane extraction of pawpaw leaf was not effective against the test bacterium and fungus. However this result contradicted the findings of Chandra et al. (2011) that the nhexane extract of pawpaw leaves possess antibacterial activities. This may be because of the hot extraction used in this study as against the cold extraction used in their study.

Temperature stability of plant extract have been reported by Doughari (2006) and this may be an indication that the bioactive compounds are heat stable and explains the ethno-botanical application process for the plants where boiling at high temperature for extended period of time are often practiced without the extracts losing their efficacy. This could be the reason for the noninhibitory activities of the n-hexane extract of pawpaw leaf against the test bacteria and fungi.

These observations indicate that the difference in activity could be due to variations in the phytochemical composition of the extracts (Arunkumar and Muthuselvan, 2009 and Yebpella et al., 2011). Also, it was observed that the potency of the activity of Carica papaya against microbes depends on the extraction solvent used. The therapeutic value of medicinal plants has been reported to lie in the various chemical constituents in it (Orhue and Momoh, 2013). In fact, active principles singly or in combination inhibit greatly the life processes of microbes, by binding with their protein molecules, acting as chelating agents (selective binding polyvalent metal ions so that the latter loses its biological activities), altering their biochemical systems, preventing utilisation of available nutrients to the microorganisms (Garrod et al., 1995).

The activities of the extracts were compared to those of antibiotics and antifungal. The antibiotic used has a higher inhibitory activity against the test bacteria compared to methanol, ethanol and n-hexane extract at low concentration. Its inhibitory activity 


\section{Antimicrobial effect of Pawpaw leaf extract in Animal Production}

was however lower than that of ethanol extract but higher than that of methanol and n-hexane at low concentration. The inhibitory activity of the control was lower than that of methanol but higher than that of ethanol and n-hexane at high and low concentrations.

The demonstration of activities against the test bacteria and fungi provides scientific bases for the local usage of the pawpaw plant extracts in the treatment of various diseases. This is very significant because of the possibility of developing therapeutic against multidrug resistant organism. Demonstration of antibacterial activity against the test isolates is an indication that there is possibility of sourcing alternative antibiotic substances in these plants for the development of newer antibacterial agents. The disparity between the activities of the extract and the standard antimicrobial drug may be due to the mixtures of bioactive compounds present in the extract compared to the pure compound contained in the standard antibiotics (Gatsing et al., 2010).

This study thus supports previous studies that Carica papaya leaves have antimicrobial potentials (Anibijuwon and Udeze, 2009; Baskaran et al., 2012). This research has however proved that papaya leaves have potential natural antibacterial and antifungal compounds. The demonstration of activity against the test bacteria and fungi provides scientific bases for the local usage of these plants in the treatment of various diseases like diarrhea, enteritis, aspergillosis, mastisis, pneumonia, tracheobronchitis, cough, osteomyelitis, aspergillosis, wounds and other infections.

\section{Conclusion}

The use of methanol-extracted pawpaw leaf as alternatives to synthetic antibiotic in animal production is effective against microbial organisms at low (200ppm) concentration. Thus the occurrence of resistance to antibiotic or its residues on animal products will be reduced.

Demonstration of antibacterial activity against the test isolates was an indication that there is possibility of sourcing alternative antibiotic substances and scientific bases for the local usage of pawpaw plant extracts for the development of newer antibacterial agents. For further studies, the effectiveness of pawpaw leaf extract should also be investigated in vivo in animal study to ascertain its effects on animal health. Such study will ascertain if pawpaw leaf extracts will confer favourable gut integrity, enable the animals to perform optimally and ensure that healthy and good quality animal products are made available to the consumers. The use of the pawpaw leaf extracts in feed formulation will be more economical to the livestock farmer compared to the cost of purchasing synthetic drugs.

However, care should be taken on the quantity of the extracts used to prevent the development of resistance by the diseasecausing agents.

\section{References}

Adam, A, Mohammed, E. A and Mohamed, S. 2014. Carica papaya is as a source natural medicine and its utilization in selected pharmaceutical application. Int. J. Pharm. pharmaceutical Sci. Vol. 6(1)

Ajani, E. O., Bamisaye, F. A. and Minari J. B. 2013. Prospects of Ethnobotanical Uses of Pawpaw (Carica papaya) J. Med. Plants Studies, 1 (4)

Anibijuwon, I. I. and Udeze, A. O. 2009. Antimicrobial Activity of Carica Papaya (Pawpaw Leaf) 


\section{Omidiwura}

on Some Pathogenic Organisms of Clinical Origin from SouthWestern Nigeria. Ethnobotanical Leaflets 13: 850-64

Arunkumar, S. and Muthuselvan, M. 2009. Analysis of pytochemical constituents and antimicrobial activities of Aloe veraL. against clinical pathogens. World J Agric Sci. 5: 572-576

Baskaran, C., Ratha-bai, V., Velu, S. and Kumaran, K. 2012. The efficacy of Carica papaya leaf extract on some bacterial and a fungal strain by well diffusion method. Asian Pacific J.Tropical Dis.; S658-S662

Brun, R., Kaminsky, M., Wagh, F. 1993. Comparative studies on antimicrobial properties of extracts of fresh and dried leaves of Carica papaya $(\mathrm{L})$ on clinical bacterial and fungal isolates. J. Ethnopharmacol. 55: $1-11$

Chandra, G., Ghosh, A., Chatterjee, S. K. and Bhattacharjee, I. 2011. Antibacterial activities of some plant extracts used in Indian traditional folk medicine. Asian Pacific J. Tropical Biomedicine. S165-S169.

Defrancesco, K. A., Cobbold, R. N., Rice, D. H., Besser, T. E. and Hancock, D. D. 2004. Antimicrobial resistance of commensal Escherichia coli from dairy cattle associated with recent multiresistant salmonellosis outbreaks. Vet. Microbiol. 98: 5561

Doughari, J. H. 2006. Antimicrobial activity of Tamarindus indica Linn. Tropical J. Pharm. Res. 5(2): 592603

Edeoga, H. O., Okwu, D. E. and Mbaebie B.O. 2005. Phytochemical constituent of some Nigeria medicinal plants Ar. J. Biotechnol., 4(7): 658-688

Forman, C. R., and Burch, J. E. 1947. Use of sodium sulphonamides as single injection specific treatment in foot rot. J. Am. Vet. Med. Assoc. 111:208-214

Garrod, L. P., Lambert, H. P. and O'Gray, F. 1995. Antibiotics and Chemotherapy, 4th Ed, Churchill, Livingstons, Edinburgh, London and New York. pp.501-512

Gatsing, D., Nkeugoauapi, C. F. N, Nkah, B. F. N., Kuiate, J. R. and Tchouanguep, F. M. 2010. Antibacterial Activity, Bioavailability and Acute Toxicity Evaluation of the leaf extract of Alchornea cordifilia Int. J. Pharmacol. 6: 173-182

Guyue, C., Hafiz, I. H., Haihong, H., Lingli, H., Menghong, D. Xiaohui A., Yulian, W., Zahid,I., Zhenli, L., and Zonghui, Y. 2014. Benefits and risk of antimicrobial use in food-producing animals. Frontiers in Microbiology volume 5 article 288

Isela, E. Juarez-Rojop, Carlos, A. Tovilla-Zarate, Dora, E. AguilarDominguez, Luis, F. Roa-de la Fuente, Carlos, E. LobatoGarcia, Jorge, L. Ble-Castillo, Leonor, Lopez-Meraz, Juan, C. Diaz-Zagoya，Deysi，Y. B ermudez-Ocana 2014 Phytochemical screening and hypoglycemia activity of Carica papaya leaf in streptozotocininduced diabetic rats. Brazilian J. Phamacognosy, Vol. 24(3): 341347.

Orhue, P. O. and Momoh, A. R. M. 2013. Antibacterial activities of different 


\section{Antimicrobial effect of Pawpaw leaf extract in Animal Production}

solvent extracts of carica papaya fruit parts on some gram positive and gram negative organisms. International Journal of Herbs and Pharmacological Research 2(4): 42-47

Maeda-Machang'u, A. D., Mutayoba,S. K., Laswai, G. H., Kurwijila, R. V.,and Kimambo, E. S., Kondela, A. and Kessy, H. 1997. Local Knowledge in animal health in different livestock production systems in Tanzania. TVA journal 16:230-255.

Mangalanayaki, R. and Nirosha, N. 2013. Antibacterial Activity of Leaves and Stem Extract of Carica papaya L. International Journal of Advances in Pharmacy,Biology and Chemistry. 2(3): 473-476

Minja, M. M. J. 1999. The Maasai wonder plants: A paper presented in at 'people and Plants' workshop held in Arusha at TPRI 15-18 March 1999

Nwofia, G. E., Ogimelukwe, P. and Eji, C. 2012. Chemical composition of leaves, fruit pulp and seed in some morphotypes of $C$. papaya $\mathrm{L}$ orphotypes. Int. J. Med. Arom. Plant 2:200-206

SAS, 2008. Statistical Analysis System, SAS users guide: statistics. SAS institute inc. cary, N.C. USA.
Satyapal, S., Anwar, S. Mohit, K., Mohammed, F. and Ashok, K. B. 2013. Antifungal activity of the Carica papaya important food and drug plant. Asian J. Plant Sci. Res. 3(1):83-86

Srinivasan, D., Sangeetha, N., Suresh, T. and Perumalsamy, P. 2001. Antimicrobial activity of certain Indian medicinal plants used in folkloric medicine. Journal of Ethnopharmacology, 74, 217-220

Sumathi, R. and Gowthami, M. 2014. Phytochemical analysis and invitro Antimicrobial activity of Aqueous and Solvent extracts of Carica papaya against clinical $\begin{array}{llllllllll}\mathbf{P} & \mathbf{a} & \mathbf{t} & \mathbf{h} & \mathbf{0} & \mathbf{g} & \mathbf{e} & \mathbf{n} & \mathbf{s} & \text {. }\end{array}$ Int.J.Adv.Res.Biol.Sci. 1(1):73-77

Yebpella, G. G., Hammuel, C., Adeyemi, H. M. M., Magomya, A. M., Agbaji, A. S. and Shallangwa, G. A. 2011. Phytochemical screening and a comparative study of antibacterial activity of Aloe veragreen rind, gel and leaf pulp extract s. Int Res $J$ Microbiol. 2:382-386

Zaria, L. T., Akiniyi, J. A. and Mshelia, E. H. 1995. Antimicrobial screening aqueous extract of five plants used folk medicine in Nigeria. West African J. Biol. Sc., 3(5): 21-26.

Received: $11^{\text {th }}$ April, 2017

Accepted: 17 July, 2017 